Volume 8, No.6, November - December 2019

International Journal of Advanced Trends in Computer Science and Engineering

Available Online at http://www.warse.org/IJATCSE/static/pdf/file/ijatcse07862019.pdf

https://doi.org/10.30534/ijatcse/2019/07862019

\title{
Study of Indonesia Vehicle Insurance for New Scheme Applied Use Based Insurance Model
}

\author{
Priatama Elko', Rifyansyah Pravasta ${ }^{2}$, Tanujaya William ${ }^{3}$, Gunawan Wang ${ }^{4}$ Emil Robert Kaburuan $^{5}$ \\ 1,2,3,4,5 Information Systems Management Department, Binus Graduate Program, Bina Nusantara University, \\ Jakarta, Indonesia, 11480, ${ }^{1}$ Elko.priatama001@ binus.ac.id, ${ }^{2}$ Pravasta.rifyansyah@ binus.ac.id, \\ ${ }^{3}$ William.tanujaya001@binus.ac.id, ${ }^{4}$ gwang@binus.edu, ${ }^{5}$ emil.kaburuan@ binus.edu.
}

\begin{abstract}
This paper purpose to create new schema for vehicle insurance company in Indonesia. The scheme of applying premium rates in Indonesia is uncorrelated when viewed from the basic principles of insurance in determining premium contributions. Groups of individuals with safe driving behavior are equated with groups of individuals who have more dangerous risk characteristics. The new schema can provide information about speed, speed acceleration, hard braking, etc. Where insurance companies can apply premium contributions from the assessment of driving behavior. The new schema is harness technology in the vehicle will recover in real time the vehicle data, including driving time, distance, and average speed, maximum speed of the driver, the amount of sharp turns, the location and the route of use of the vehicle which will be automatically stored in the database. Not only supported by technology but also the new schema vehicle in Indonesia acquired fairness in premium insurance price determination between good behavior driver and bad behavior driver.
\end{abstract}

Key words: Insurance, Pay-As-Your-Drive, Pay-How-You-Drive, Transportation, Telematics, Usage Based Insurance.

\section{INTRODUCTION}

The growth of vehicles, especially four-wheelers in Indonesia is proportional to the risk of accidents. According to data published by the traffic police, more than 100,000 accidents occurred in 2018, with an average of almost 300 accidents per day which resulted in material losses and loss of life. The age range of 15 to 25 years contributes the most to the number of accidents. This age group is the most vulnerable in Indonesia. This observation usually occurs in many countries. Young people are not aware of risky driving behavior and they are still beginners in driving vehicles. With increasing experience, drivers will learn more about their limitations and develop safer driving attitudes. Drivers who have experience can describe driving skills to avoid the risk of accidents [1] .

In Indonesia, the vehicle insurance premium rate is regulated by an authorized regulator, the Financial Services
Authority (OJK). Where in the regulation it is stated that the determination of insurance premium rates is determined by the place of registration of the vehicle, type of vehicle and total sum insured. This is when associated with accident data based on vehicle age groups in Indonesia, there will be a misconception in determining motor vehicle insurance rates.

Viewed from the basic principle of insurance, which is a risk transfer agreement, where the driver transfers the risk that can result in financial losses to the insurance company by giving premium contributions. In principle, companies conduct grouping of individuals who have the same risk characteristics to be able to determine the premium rate for each individual in the group [2] .

The scheme of applying premium rates in Indonesia is uncorrelated when viewed from the basic principles of insurance in determining premium contributions. Groups of individuals with safe driving behavior are equated with groups of individuals who have more dangerous risk characteristics. So they are charged the same premium contribution rate [3]. In its analogy, groups of individuals at lower risk are forced to buy the possibility of a higher risk than they should. Likewise, the opposite group of individuals who have a higher risk means buying the possibility of a lower risk than they should. Current schemes are also considered not to affect psychological factors that can improve driving behavior.

To illustrate the premium contribution to risk characteristics, a more relevant scheme to describe it is to use the parameters of assessment of driving behavior and the environment. Driving safety can be significantly affected by innovative insurance policies [4]. Implement lower premium rates for safe driving behavior and a safer environment than dangerous driving and environments. This information can now be obtained with a device that provides various data as a source of assessment of driving and environmental behavior.

This tool can provide information about speed, speed acceleration, hard braking, etc. Where insurance companies can apply premium contributions from the assessment of 
driving behavior[3]. Which further information can be openly presented to the driver? The report can be in the form of information on maximum speed, acceleration or hard braking, violation of speed limits on certain roads, fuel consumption and others [5]. In this way the driver can make the report as a reference for later improvising his driving behavior.

\section{LITERATURE REVIEW}

Vehicle insurance does exist to provide protection facility to driver against injury from accident in the traffic. The policyholder used to buy a pack of vehicle insurance with specific term from the company [6].

In Indonesia, hazard and disserve behavior while driving vehicles is a major concern in the field of transportation and insurance companies. Hazard behavior in terms of insurance context refer to situations where the insurance holder does not care about safety or reduce the risk of driving while having insurance [7].

Basically, someone has obtained insurance and will get an incentive might become careless in driving, unless the premium insurance calculated based on their behavior while driving. Policyholder will gain their good behavior for driving and reduce accident potential in the traffic [8].

Adverse behavior when driving makes the insurance company can establish the provisions written in the insurance contract and provide premium information that must be paid by the driver in accordance with calculations based on driving behavior. It suitable for Indonesia because insurance companies adjust their premium cost calculation based on age, sex, type of vehicle.

The reasons of driver behavior have not been used as basis calculation are unavailable data and inconvenient to obtain. The calculation premium cost based on age, sex, and type of vehicle considered incriminate driver who have good behavior and high alertness because they have to pay same cost as the driver who have adverse behavior and potentially dangerous [8].

When there is no significant difference between good behavior driver and hazard behavior driver, it might be main concern in the policyholder and insurance company. The insurance theory model explains that when the insurance market provides services with high risk and high premium, policyholder potentially action in high risk level. This model shows there is a relationship between risk level and insurance coverage [9].

With current technology advances, the use of device technology is part of the solution to solve the incrimi0nate between policyholder. Currently the use of Usage Based Insurance (UBI). The use of the model calculates premium cost based on distance, speed and fuel usage by driver.
A research result recommend the variables based on distance adjusted to the risk, geography conditions, and driver behavior to determining price of insurance premium [10].

The main idea is insurance company must be able to provide facilities to record the distance and driver behavior as a basis to determine premium cost policyholder[11].

Insurance company in several countries implement UBI program for their consumer such as US, England, Australia, Netherlands, Spain, Japan, and Italy[12]. UBI is a program utilizes telematics technology to integrate information and technology including transportation information, receiving and storing information related to object via telecommunication devices. Some of these programs offer policyholder to receive discount for premium cost if using sensors to monitoring vehicle mileage. Additionally, the UBI program equipped with sensor also provide combination of technology such as hard braking, distance travel, vehicle speed, time and days of vehicle use to calculate the risk of driver [12]. In term of regulation and technology, there are rising several challenges. For example, data protection and privacy trigger leakage of policyholder [1].

The UBI program is limited in usage only for policyholder who have signed premium contract. The reason are high cost, compatibility, and willingness data recorded [1] to calculate the distance and speed of vehicle is not a single technology, the UBI program abuse GPS. However, the prospect of the usage of UBI program is make people to increase their awareness drive behavior to drive well.

Insurance companies should consider the first customer's concern about their personal data and transmission to give customer trust and perceive enjoyment when choose the UBI program [13].

\section{RESEARCH METHOD}

Based on finding literature review, technology implementation in insurance company will be supported. Technology usage implement sensor installed on vehicle. The Usage Based Insurance programs can be applied selfreporting-based insurance, Pay-As-You-Drive (PAYD)/PayAs-You-Go (PAYG), Pay-How-You-Drive (PHYD).

Measurement of the premium supported to application which installed on smartphone to monitoring driver behavior. UBI indicator are distance, hard breaking behavior, and speed [8]. Self-reporting-based insurance use indicator mileage as basis of calculation of premium. PAYD indicator are distance, travel route, travel time, travel frequency, type of vehicle, breaking behavior, seatbelt, and mobile phone usage [3]. Device will send all mileage data to insurance company and calculate the premium [12]. PHYD device send driver driving style and calculate the risk of the driving[3]. 
Priatama Elko et al., International Journal of Advanced Trends in Computer Science and Engineering, 8(6),November -December 2019,2726 - 2729

With wearable technology combination, traffic as innovation, smartphone usage, and indicators [14], change of vehicle insurance scheme in Indonesia have big chance to implement.

\subsection{Pay-As-Your-Driver (PYAD)}

Some of studies focus on relationship distance of vehicle with traffic hazard possible to increase risk and involved driver in accident [3]. It shows that mileage provide explanatory power when combined with space and behavior information. This reality arising fairness cost premium between short mileage driver and long mileage driver.

\subsection{Pay-How-You-Drive (PHYD)}

Evaluating Pay-As-You-Drive system now have many weakness and disadvantage because the system is only focus on mileage but not driver behavior.

Driver behavior is important to evaluate the risk an accident than calculate cost. Pattern of driving each driver is a significant issue to convert to accident risk modeling, because each driver has different behavior on traffic [3].

\section{RESULT OF DISCUSSION}

According to what has been discussed above about how a risk affects the price of the premium of the clients of the insurance companies [15], as well as the magnitude of the accident rate in Indonesia. Therefore, we need a method to grant premium rates that are in accordance with the behavior of insurance clients, giving a fair premium according to the behavior of insurance agents that will play an important role in the modern world, it is possible with existing technological developments.

Insurance in Indonesia can use the PAYDI method that provides protection against the risk of death, which gives a policy value to the risk of death of all registered persons, who currently have difficulties in providing adequate values for each client because they do not have the data to do it. Analyze the risk of each customer. Therefore, in this modern time, insurance companies can use Usage Based Insurance (UBI) technology.

UBI is a device connected to each vehicle to obtain data that analyzes the risk of death in driving. The UBI technology incorporated in the vehicle will recover in real time the vehicle data, including driving time, distance, and average speed, maximum speed of the driver, the amount of sharp turns, the location and the route of use of the vehicle which will be automatically stored in the database. Then the system will be processed in a risk analysis of driving behavior.

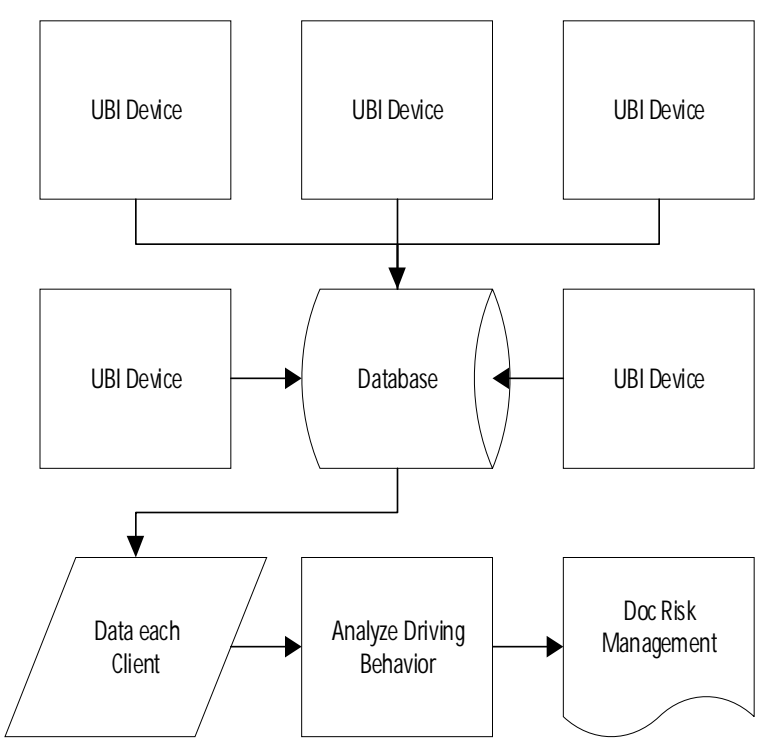

Figure 1: Flow of Usage Based Insurance Scheme

The following data will be taken from the UBI device. In the diagram above, it is visible that all the UBI devices registered by the company with all the security that protects them and preserves the confidentiality of the customer's data are send directly to the Cloud database, so that there will be no local database in the device to be safer. Then from the data automatically collected in the database, the property of each device has been mapped; the data is automatically analyzed according to the parameters defined by the insurance company, namely the ranking of each user who will become an indicator. Risk document to become the basis of insurance price. Risk document must be aligned with ISO 9000 for quality assurance to develop application in order to following international standard models which are internal and external quality and quality in use or run the software application[16].

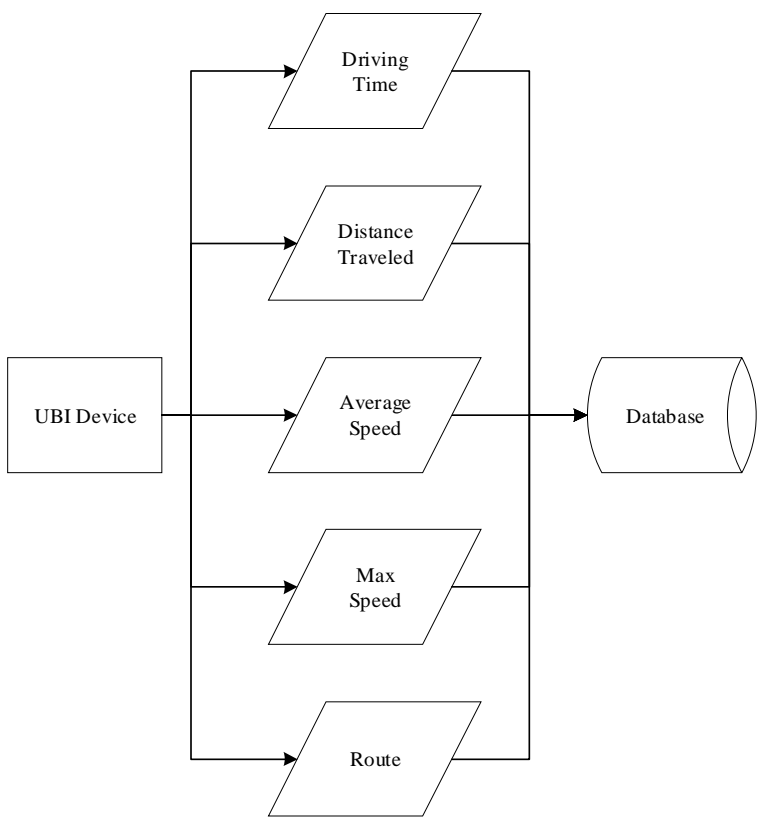

Figure 2: Variables of Usage Based Insurance 
As can be seen above, five important points will be considered in the UBI device data, which will then be as a risk assessment tool for driving deaths. With UBI devices, insurance companies can offer reasonable prices that can increase the profitability of the company. To save five important points above, UBI technology able to embed 4G$5 \mathrm{G}$ due to vehicle growing every year[17].

With UBI devices, insurance companies can provide reasonable prices for policies that can potentially increase the company's profitability.

In Indonesia, the government has issued a regulation on this issue issued by the Financial Services Authority (OJK) where, if you wish to implement the previous device. Legitimate insurance companies in Indonesia must go through a verification process by OJK through sandbox that aims to demonstrate to the government that the UBI process is in accordance with the provisions established by the government, in particular with respect to the Protection of the privacy of Indonesian citizens.

\section{CONCLUSION}

From the above results it can be concluded that in Indonesia it is very possible or very open to carry out the UBI tenure in the insurance companies due to the governmental regulations (law) that has been supporting to implement the use-based insurance (UBI).

By using this technology, the problems that exist in the insurance company will be resolved and the risk of loss in the value of the insurance that does not have data can be avoided by the presence of real-time data of the insured users or cars.

\section{REFERENCES}

[1] Y. Yao, "Evolution of Insurance: A TelematicsBased Personal Auto Insurance Study," 2018.

[2] R. J. Finger, "Chapter 6 RISK CLASSIFICATION," pp. 287-342.

[3] D. I. Tselentis, G. Yannis, and E. I. Vlahogianni, "Innovative insurance schemes: pay as / how you drive," Transp. Res. Procedia, vol. 14, pp. 362-371, 2016.

https://doi.org/10.1016/j.trpro.2016.05.088

[4] J. Zantema, D. H. Van Amelsfort, M. C. J. Bliemer, and P. H. L. Bovy, "Pay-as-You-Drive Strategies Case Study of Safety and Accessibility Effects," no. 2078, pp. 8-16, 2008.

https://doi.org/10.3141/2078-02

[5] T. Toledo, O. Musicant, and T. Lotan, "In-vehicle data recorders for monitoring and feedback on drivers ' behavior," vol. 16, pp. 320-331, 2008.

https://doi.org/10.1016/j.trc.2008.01.001

[6] G. City, C. E. Gay, G. Hayward, S. C. Cielocha, and T. Binion, "(12) Patent Application Publication (10) Pub. No.: US 2014/0310028A1," vol. 1, no. 19, 2014.

[7] R. Zeckhauser, "Medical insurance: A case study of the tradeoff between risk spreading and appropriate incentives," J. Econ. Theory, vol. 2, no. 1, pp. 1026, 2004.

https://doi.org/10.1016/0022-0531(70)90010-4

[8] Y. Ma, X. Zhu, X. Hu, and Y. Chiu, "The use of context-sensitive insurance telematics data in auto insurance rate making," Transp. Res. Part A, vol. 113, no. September 2017, pp. 243-258, 2018.

[9] T. Quarterly, "Equilibrium in Competitive Insurance Markets : An Essay on the Economics of Imperfect Information Author ( $\mathrm{s}$ ): Michael Rothschild and Joseph Stiglitz Published by: Oxford University Press," vol. 90, no. 4, pp. 629-649, 2013.

[10] A. Greenberg, "Designing pay-per-mile auto insurance regulatory incentives," Transp. Res. Part $D$, vol. 14, no. 6, pp. 437-445, 2009. https://doi.org/10.1016/j.trd.2009.01.003

[11] M. Ayuso and J. P. Nielsen, "Improving automobile insurance ratemaking using telematics : incorporating mileage and driver behaviour data," 2017.

[12] S. Husnjak, D. Peraković, I. Forenbacher, and M. Mumdziev, "Telematics System in Usage Based Motor Insurance," Procedia Eng., vol. 100, pp. 816-825, 2015.

[13] R. Wiegard and M. H. Breitner, "Smart services in healthcare: A risk-benefit-analysis of pay-as-youlive services from customer perspective in Germany," 2017. https://doi.org/10.1007/s12525-017-0274-1

[14] J. Loia, B. Alexander, C. Johnson, J. Carducci, and L. Valley, "United States Patent [191," 1989.

[15] M. Jill, “( 12 ) United States Patent,” vol. 1, no. 12, 2001.

[16] M. Aminu et al., "International Journal of Advanced Trends in Computer Science and Engineering Available Online at http://www.warse.org/IJATCSE/static/pdf/file/ijatcs e6081.32019.pdf Measuring Software Product Quality using ISO 9126: A Systematic Review," vol. 8, pp. 327-336, 2019. https://doi.org/10.30534/ijatcse/2019/6081.32019

[17] R. Khdhir and A. Belghith, "International Journal of Advanced Trends in Computer Science and Engineering 5G LTE-A Cognitive Multiclass Scheduling Scheme for Internet of Things," vol. 8, no. 5, pp. 2485-2491, 2019.

https://doi.org/10.30534/ijatcse/2019/94852019 